\title{
Review of the Malagasy Anthobosca, the Bizarre and the Sublime (Hymenoptera: Tiphiidae: Anthoboscinae)
}

\author{
LYNN S. KIMSEY \\ Bohart Museum of Entomology, Department of Entomology, One Shields Ave., University of California, Davis 95616, USA \\ E-mail: lskimsey@ucdavis.edu
}

\begin{abstract}
The Malagasy tiphiids in the genus Anthobosca are revised, with description of eight new species, including fisheri, harinhalai, mahajangaensis, castanea, namorokaensis, nigrimacula, toliaraensis and hallucigenia spp. nov. There are fourteen described species of Anthobosca recorded from Madagascar including the new ones below. A key to species, distribution maps and illustrations are given.
\end{abstract}

Key words: Tiphiidae, Anthobosca, Madagascar, new species, key

\section{Introduction}

The island of Madagascar has a relatively diverse, though seemingly recently derived tiphiid fauna. Unlike so many of the plants and animals found on the island, there are no endemic tiphiid genera on the island. This pattern is seen also in the wasp family Chrysididae (Kimsey \& Bohart 1991). The least derived tiphiid subfamily (Kimsey 1996), Anthoboscinae, is particularly species-rich on Madagascar, with fourteen species. Anthoboscinae occur primarily in the Southern Hemisphere (Africa, Australia and South America), with the largest number of species in the south temperate regions. However, there are two notable exceptions to this distribution, Anthobosca sauakinensis Magretti from the Arabian Peninsula (Bartalucci 2005, Magretti 1884) and Lalapa lusa Pate from southwestern North America (Pate 1947).

The California Academy of Sciences' Arthropods of Madagascar Project revealed a much more diverse tiphiid fauna than previously recorded, including one of the most bizarrely modified tiphiid species yet seen, Anthobosca hallucigenia sp. nov., described below, which has unique spoon-like expansions of metasomal sterna II and III and a longitudinal, medial facial carina. Four previously published Anthobosca species are known from Madagascar (Bartalucci 2005). Unfortunately, the extreme sexual dimorphism in most Anthobosca species makes it difficult to associate the sexes.Of the previously described species, the unusually large size and distinctive coloration of male and female A. insularis F. Smith make the sex association straightforward. Sex associations among the remaining described species and the ones described below are less clear. As with other tiphiid species body size in Anthobosca is fairly variable with the largest individuals in a species often twice the length of the smallest ones. Females have few useful characteristics, and three of the four previously described Malagasy species are based on females. The study below focuses on males. The two species previously described from females may turn out to be synonymous with two of the male species discussed below, but until a reliable way of associating the sexes can be found, it is not possible to sort this out. 


\section{Key to the Malagasy species of Anthobosca}

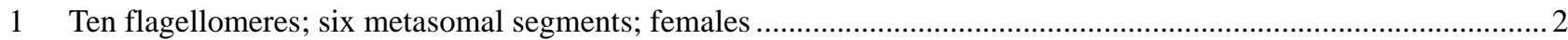
Eleven flagellomeres; seven metasomal segments; males......................................................................... 4

2 Head, mesosoma and metasoma brown; wing membrane amber-tinted; body length over 25 mm...insularis F. Smith

- Head, mesosoma and metasoma blackish or blackish and red, often with whitish spots; body length less than 15 mm

3 Metasoma red, terga II and III without whitish lateral spots. dimidiata Bartalucci Metasoma black to dark brown, with whitish lateral spots on terga II and III. ....................... madecassa Krombein

4 Metasomal sterna II and III with large spoon-like ventral projections (Fig. 4); flagellomeres with ovoid tyloids on VI-XI (Fig. 4) and large ovoid flat patch on V-X; metasoma with extensive yellow markings hallucigenia Kimsey, new species

- Metasomal sterna II and III unmodified, without projections; flagellomeres absent or present on VI-X or VII-XI; metasoma without yellow markings

5 Body length 17-20 mm; wings dark amber-tinted; flagellomeres without tyloids; tegula brown .....insularis F. Smith

Body length $11 \mathrm{~mm}$ or less; wings untinted; three or more flagellomeres with tyloids; tegula white ..................... 7

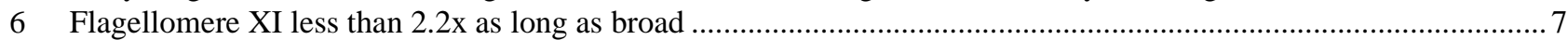

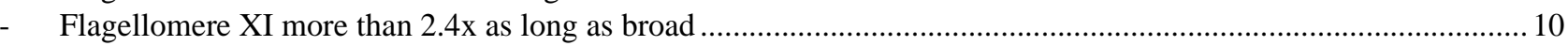

7 Flagellomere VIII without tyloid; clypeus entirely white, evenly convex with narrow ventrally facing flattened surface ...................................................................................................................................micromeria Bartalucci

Flagellomere VIII with tyloid; clypeus variously colored, without ventrally facing flattened surface ......................8

8 Flagellomere VII with small, ovoid tyloid............................................................. nigrimacula Kimsey, new species

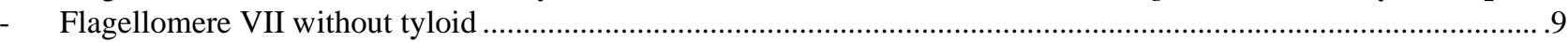

9 Volsella broadest dorsally, dorsal lobe oriented horizontally (Fig. 34); paramere apex whitish .....

Volsella broadest submedially, dorsal lobe oriented diagonally (Fig. 25); paramere apex brown toliaraensis Kimsey, new species castanea Kimsey, new species

10 Paramere apex white; flagellum strongly bicolored brown to black dorsally and yellow ventrally; digitus extending

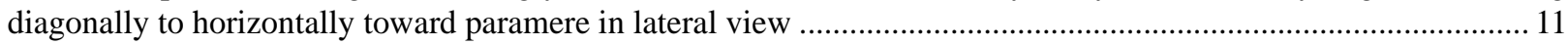
Paramere apex brown; flagellum brown to black, may be slightly paler ventrally; digitus extending diagonally

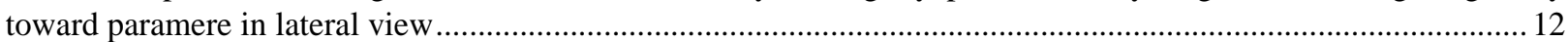

11 Volsella broadest dorsally, digitus horizontally oriented in lateral view (Fig. 20); clypeus gently convex medially, entirely white or less commonly bicolored, black and white..........................mahajangaensis Kimsey, new species Volsella narrowed dorsally, digitus oriented obliquely in lateral view (Fig. 22); clypeus flattened medially, entirely brown or bicolored brown and black .namorokaensis Kimsey, new species

12 Flagellomere XI 2.3-2.4x as long as broad; digitus horizontally oriented in lateral view (Fig. 16) fisheri Kimsey, new species

- $\quad$ Flagellomere XI 2.6-3.0x as long as broad; digitus diagonally to vertically oriented in lateral view (Fig. 18). harinhalai Kimsey, new species

\section{Anthobosca castanea Kimsey, new species}

Figs. 5, 15, 25, Map 1

Diagnosis. This species can be distinguished from micromeria Bartalucci, which it most closely resembles, by the bicolored clypeus and the presence of a tyloid on flagellomere VIII.

Male. Body length $4 \mathrm{~mm}$. Head: inner eye margin slightly emarginate; flagellomere I as long as broad; flagellomeres II and XI twice as long as broad, flagellomeres VIII-X each with one tyloid; clypeal apex broadly truncate. Mesosoma: hindleg unmodified. Metasoma: segment 1 longer than broad; sternum VIII thickened apex broadly triangular, slightly longer than broad, apical margin spinose. Genital capsule (Figs. 5, 15, 25): gonocoxa broadest basally, narrowed medially, broadly rounded apically in dorsal view; aedeagus narrow, about 10x as broad as long, apical lobes narrowly separated; volsella dorsal lobe extending diagonally from behind dorsal lobe of gonocoxa toward paramere, largely obscured by paramere and gonocoxa in lateral view; paramere basally strongly tapering toward base, $4 \mathrm{x}$ as long as broad, apical lobe about twice as long as broad in ventral view. Punctation: body with dense small, contiguous punctures. Vestiture: silvery. Coloration: head, mesosoma and metasoma black, with pale yellow to whitish markings; clypeus white, with black dorsal 
margin; mandible white, with dark apex; underside of scapal apex white; whitish band along inner eye margin; flagellum bicolored, top black, underside orange; small whitish spot behind eye near vertex; pronotum with transverse whitish band along posterior margin and ventral whitish spot; tegula and wing vein bases white; tarsi, trochanters, palps and tibial spurs whitish; tibiae and femora partly whitish; paramere apical lobe whitish.

Female. Unknown.

Type material. Holotype $\delta^{\lambda}$ : Mahajanga Prov., Parc National d'Ankarafantsika, Ampijoroa Station Forestiére, 40 km 306 nw Andranofasika, 130 m, 26 Mar.-1 Apr. 2001, 1619.15S 4638E, Fisher, Griswold, et al., malaise trap in tropical dry forest, BMF3520 (CAS). Paratypes: 4 ठठ: 2 ठ Amborovy, 6 km ne Mahajanga, 18/iv/1994, 1540S 4620E, M. Wasbauer; 1 đ̇: Toliara prov., Forêt de Mahavelo, Isantoria River, 110 m, 28/i-1/ii/2002, 244530S 46926E, Fisher, Griswold et al. colrs., MT, BLF 3237 (BME. CAS).

Etymology. Anthobosca castanea is named for the bicolored, partly brown clypeus.

Distribution. Map. 1.

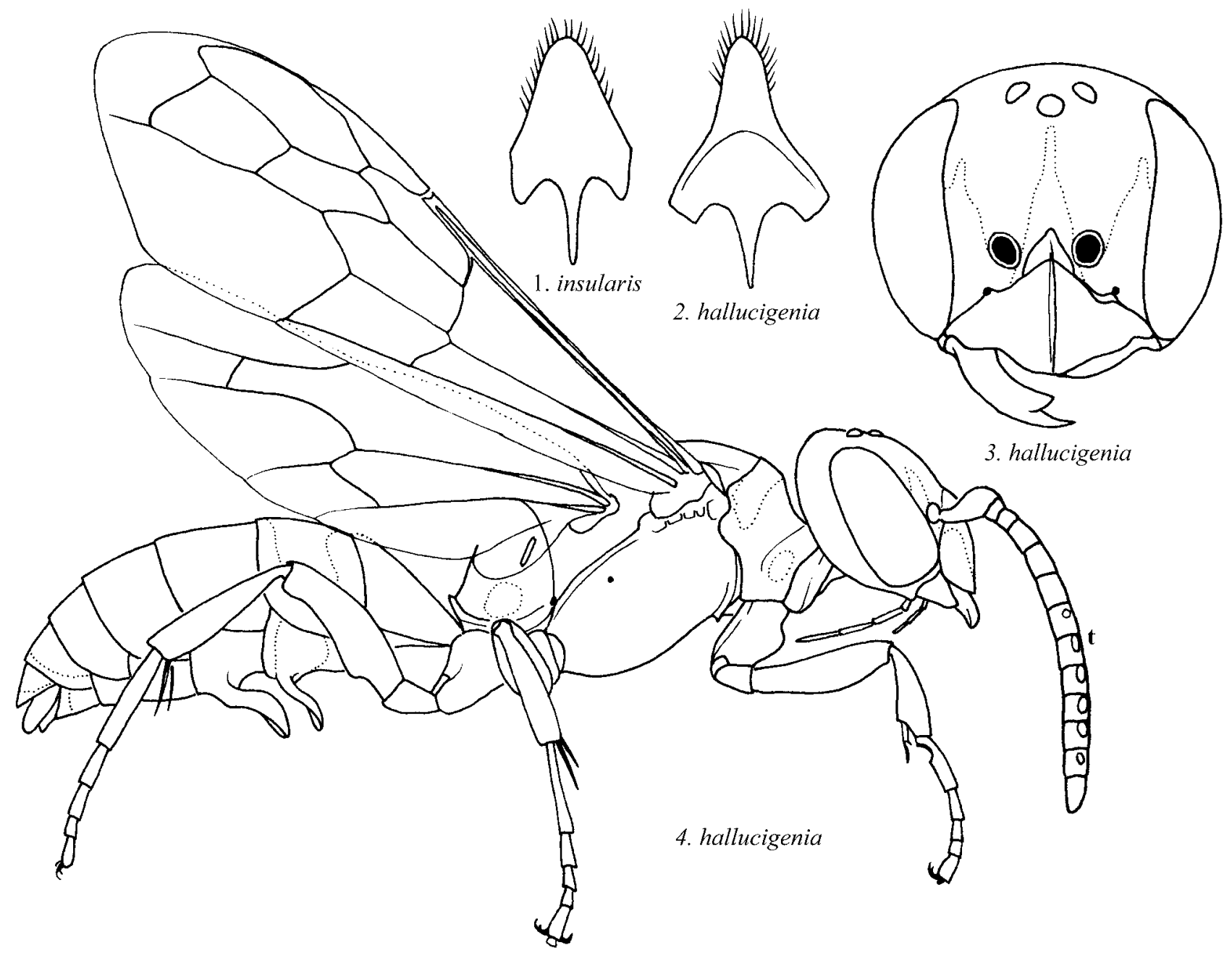

FIGURES 1, 2. Ventral view of male sternum VIII. 3. Male face. 4. Lateral view of body. Abbreviation: $t=$ tyloid.

\section{Anthobosca dimidiata Bartalucci \\ Map 1}

Anthobosca dimidiata Bartalucci 2005:1082. Holotype +; Madagascar: Tulear Berenti, 12 km northwest Amboasary (LONDON). 


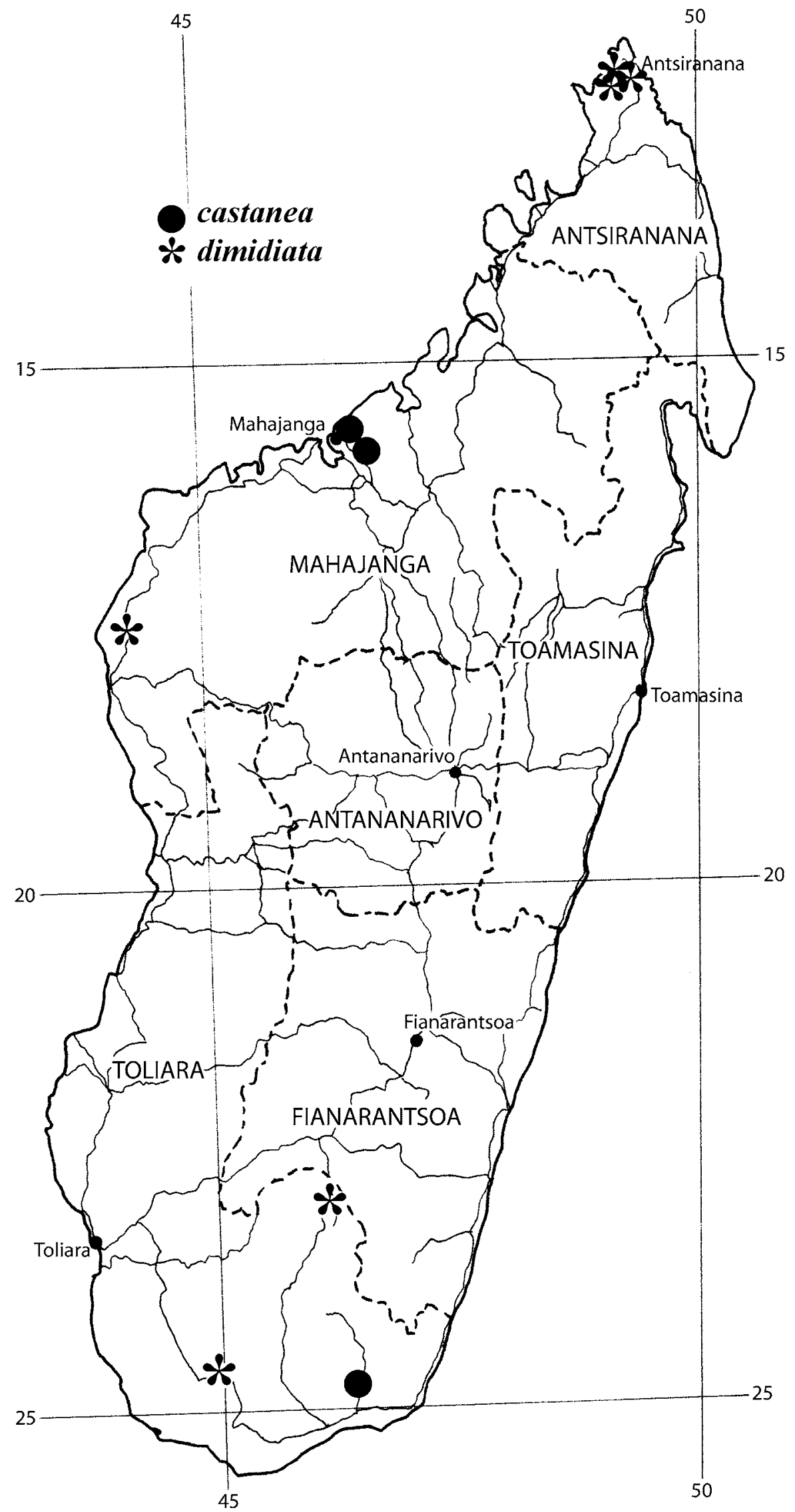

MAP 1. Distribution of Anthobosca castanea Kimsey, new species, and Anthobosca dimidiata Bartalucci. 
Diagnosis. Anthobosca dimidiata is a distinctive species; females can be easily recognized by the entirely red metasoma and all-black mesosoma.

Male. Unknown.

Female. Body length $7 \mathrm{~mm}$. Head: flagellomeres I and II 1.6x as long as broad; flagellomere X 3x as long as broad; clypeus broadly truncate apically, truncation wider than interantennal area; head broader than long. Punctation: punctures sparse and tiny on head and mesosoma, tiny and dense on metasoma. Vestiture: body with pale brownish setae. Coloration: head, antenna, mesosoma and propodeum blackish; tibial spurs whitish; metasoma entirely red, without pale white lateral spots.

Distribution. Toliara Prov.: $12 \mathrm{~km}$ nw Amboasary (Map 2); Only the type was seen. The type specimens were collected in May.

\section{Anthobosca fisheri Kimsey, new species}

Figs. 6, 16, 26, Map 2

Diagnosis. The most distinctive male features of this species are the mostly black clypeus, brown paramere dististyle, horizontally oriented volsella and flagellomere XI more than $2.3 \mathrm{x}$ as long as broad. The dark clypeus, long flagellomere XI and brown dististyle most closely resemble that of harinhalai, and the shape of the aedeagus and paramere resembles that of castanea.

Male. Body length 4-8 mm. Head: inner eye margin slightly emarginate; flagellomere I as long as broad, flagellomere II $1.5 \mathrm{x}$ as long as broad, flagellomere XI $2.3-2.4 \mathrm{x}$ as long as broad; flagellomeres VIII-X each with one tyloid; clypeal apex ventral truncation slightly indented medially. Mesosoma: hindleg unmodified. Metasoma: segment 1 longer than broad; sternum VIII thickened apex about as broad as long, apical margin spinose. Genital capsule (Figs. 6, 16, 26): gonocoxa broadest submedially in dorsal view; aedeagus broad 3.5-4.0x as long as broad, apical lobes widely separated; volsella dorsal lobe extending horizontally from behind dorsal lobe of gonocoxa toward paramere, largely obscured by paramere and gonocoxa in lateral view; paramere basal part 2.5-3.0x as long as broad and narrowest submedially apical lobe $3 \mathrm{x}$ as long as broad in ventral view. Punctation: body with dense, small, contiguous punctures, except clypeus medially nearly impunctate. Vestiture: silvery. Coloration: body black, with pale whitish, brown or dark yellow markings; flagellum black; clypeus entirely black or black with small pale lateral spot, sometimes with paler spot medially; scape with small apical yellowish band; flagellum dark; inner eye margin with whitish band; mandible reddish medially; mandible black to dark reddish brown; palps dark basally, whitish apically; small whitish spot behind eye near vertex; pronotum with transverse whitish band along posterior margin and small ventral whitish spot; femoral apices and tibial bases whitish; foretibia and tarsus red; mid and hindtarsi whitish basally becoming brown apically; paramere lobe dark brown; tegula whitish; wing veins whitish near base, remainder dark brown; wing membrane untinted.

Female. Unknown.

Type material. Holotype $\delta^{~}$ : MADAGASCAR: Toliara Prov. Forêt de Mahavelo Isantoria River, 110m, 28/i-1/ii/2002, 24453S 46926E, Fisher, Griswold et al., malaise trap, BLF5237 (CAS). Paratypes 14 ठ̊ં; 4

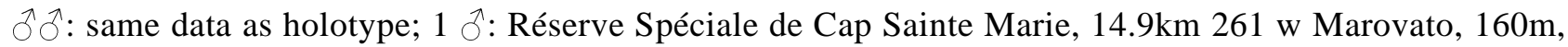
13-19/ii/2002, 253540S 45849E, Fisher Griswold et al., malaise trap, BLF5651; 1 đ: $30 \mathrm{~km}$ e Sakariha, 21/ iii/1994, 2246.20S 4450.43E, M. Wasbauer; 1 đ : Isalo National Park, Hotel Relias de la Reine, west of Ampoza, 2239S 4520E, 18/iii/1994, M. Wasbauer; 1 đ: Parc Nat. Isalo, west of Ampoza, 19/iii/1994, 2236S 4519E, M. Wasbauer; 2 ठぇ: Toamasina Prov., Andasibe National Park, 16-23/xi/2001, 1855.58S 4824.47E, R. Harin'Hala, malaise trap, 1025m, MA01-08B-20; 1 đ̃: Mahajanga Prov., Parc National d'Ankarafantsika, Ampijoroa Station Forestière, 40 km nw Andranofasika, 130 m, 26/iii-1/iv/2001, 1619.15S 4648.38E, Fisher, Griswold et al., BLF3520; 1 § : Antsiranana Prov., Réserve Spéciale de l'Ankarana, 1251.49S 4913.33E, 210 m, 16-20/ii/2001, malaise trap, Fisher, Griswold et al., BLF3011; 1 đ : Diego Suarez [Antsiranana] Prov., Parc National Montagne d'Ambre, 960 m, 213-26/i/2001, Irwin, Schlinger \& Harin'Hala, malaise trap, 

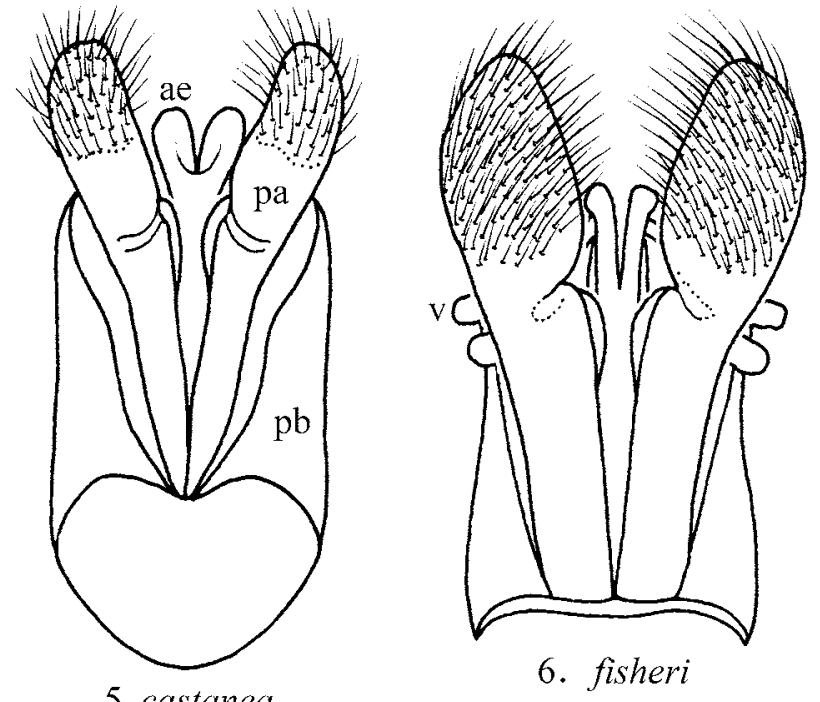

6. fisheri

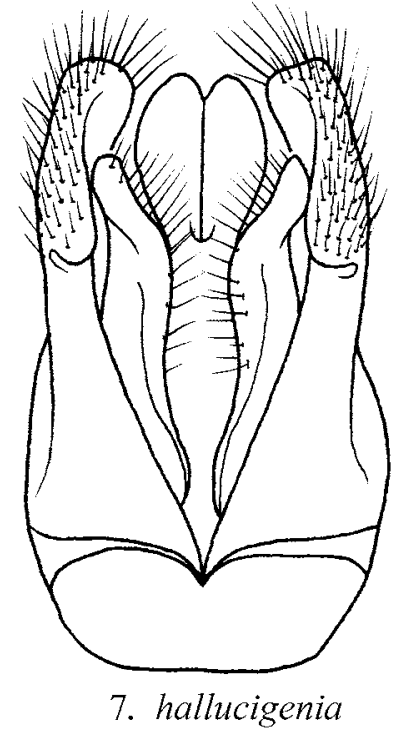

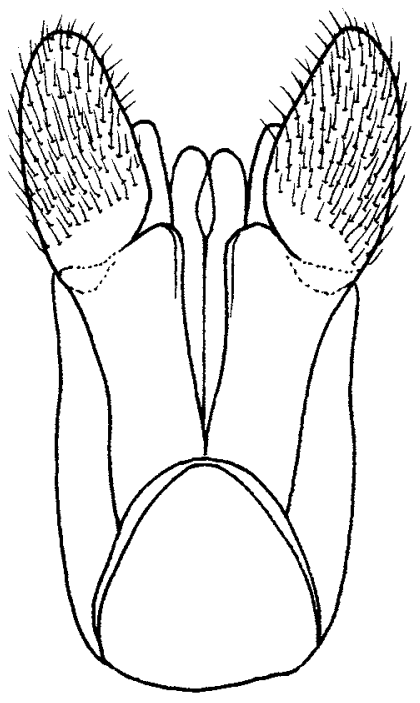

8. harinhalai

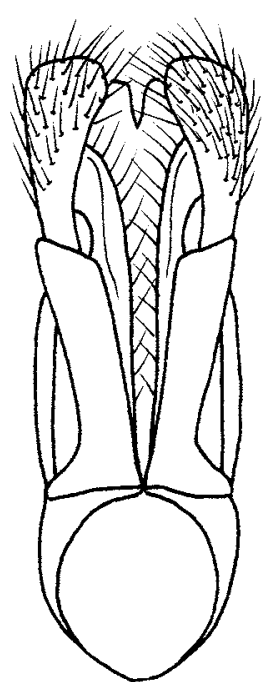

9. insularis

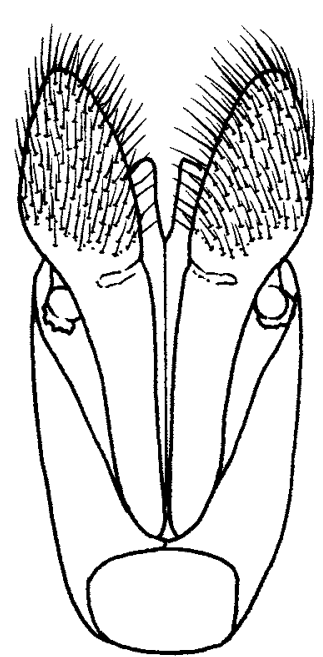

10. mahajanensis

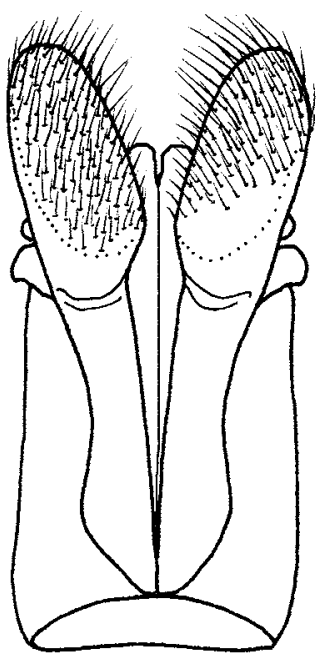

11. micromeria

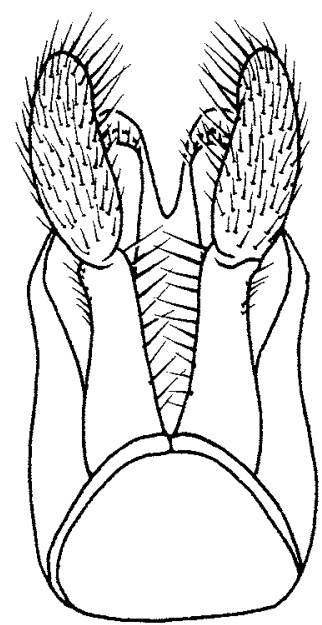

12. namorokaensis

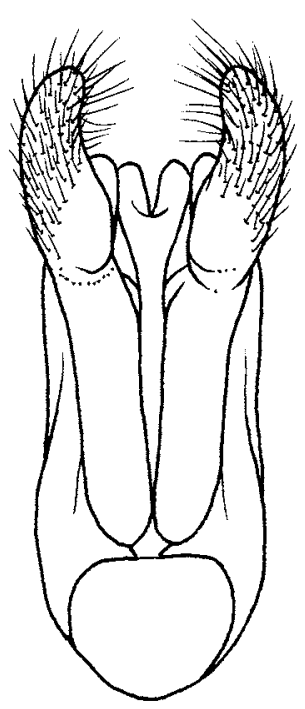

13. nigrimacula

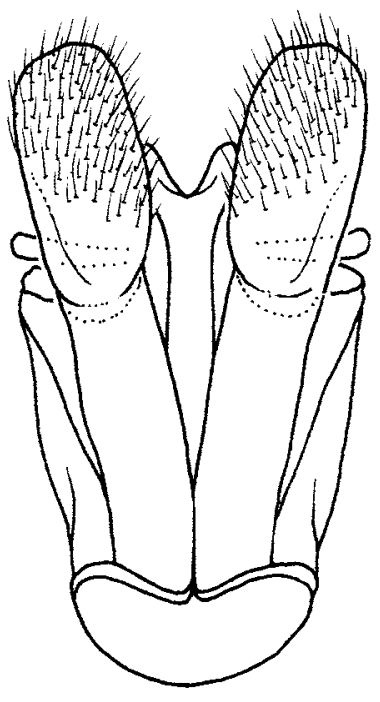

14. tolaraensis

FIGURES 5-14. Male genital capsule. ventral view. Abbreviations: $\mathrm{gc}=$ gonocoxa, $\mathrm{pb}=$ paramere base, $\mathrm{pa}=\mathrm{paramere}$ apical lobe, $\mathrm{pv}=$ penis valve, $\mathrm{v}=$ volsella . 


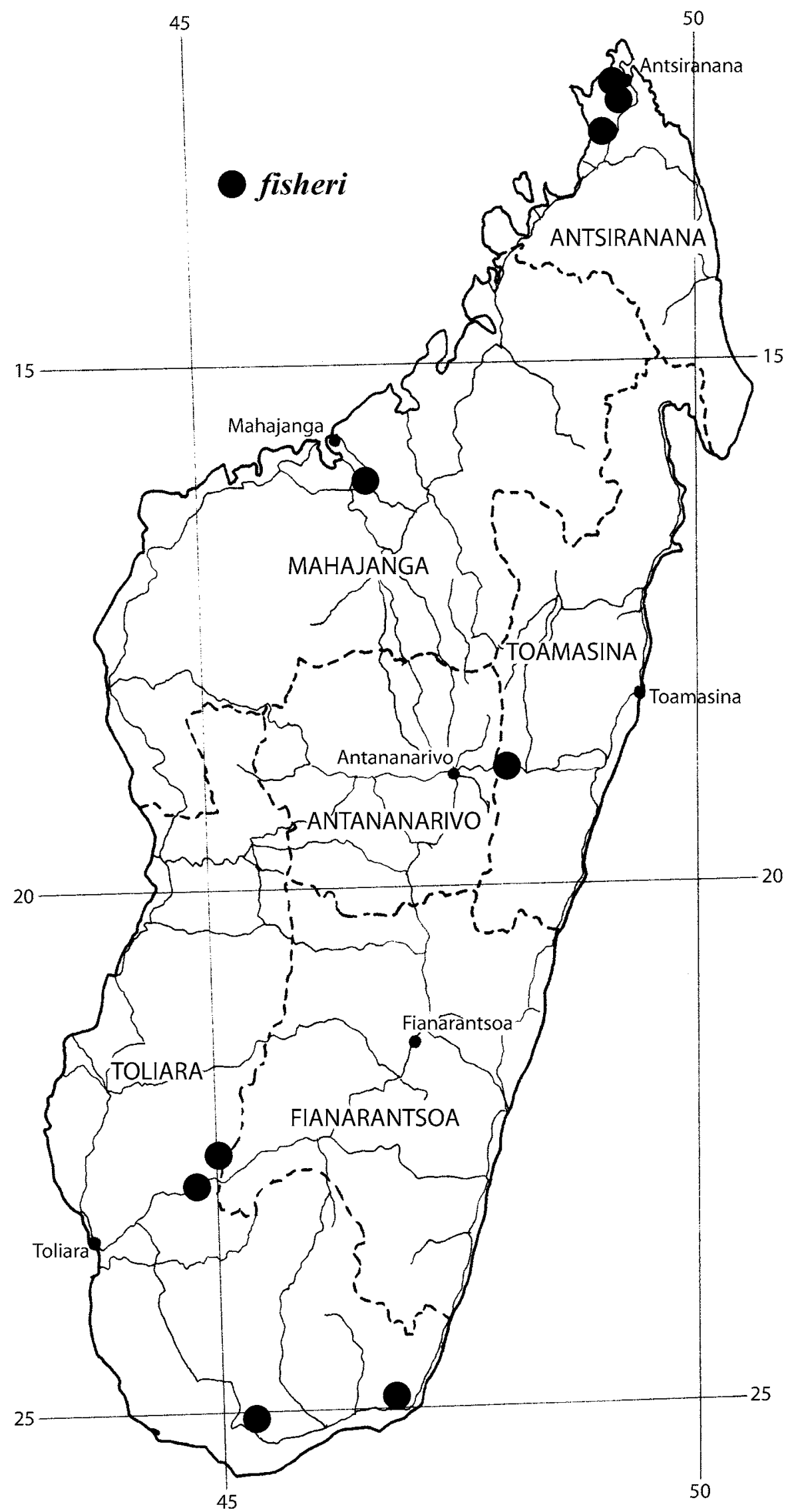

MAP 2. Distribution of Anthobosca fisheri Kimsey, new species. 


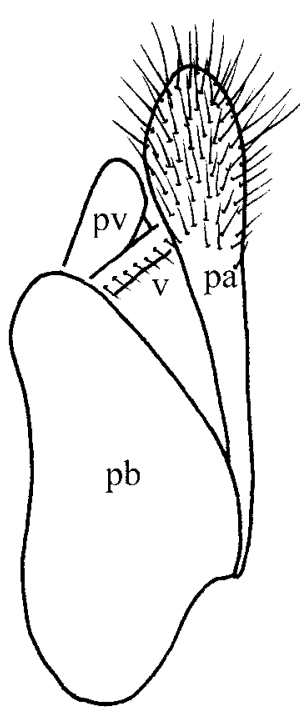

15. castanea

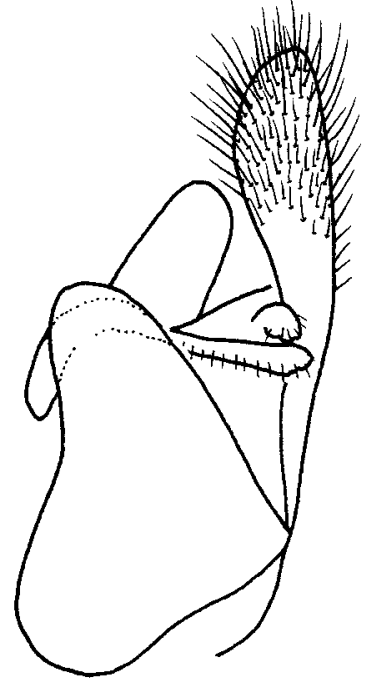

16. fisheri

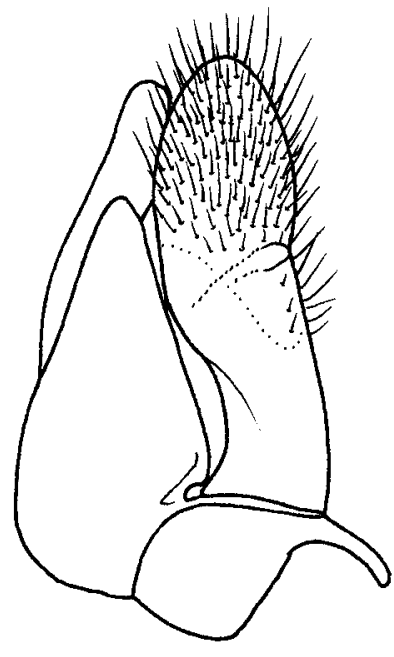

17. hallucigenia

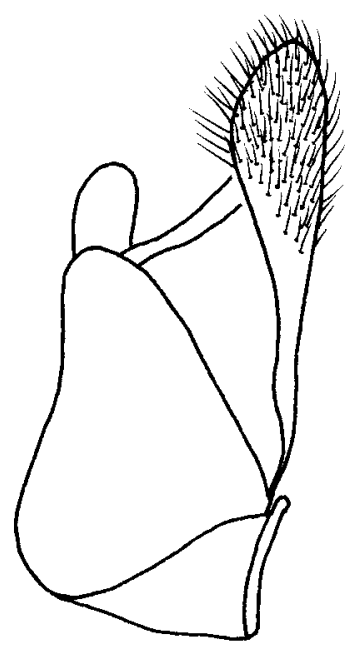

18. halinharai

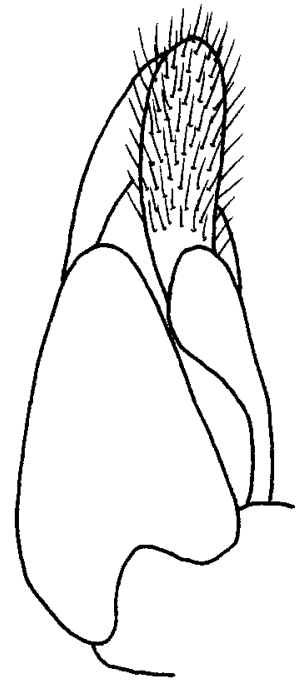

19. insularis

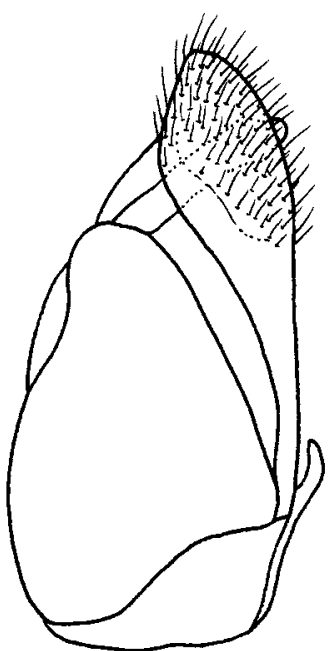

22. namorokaensis

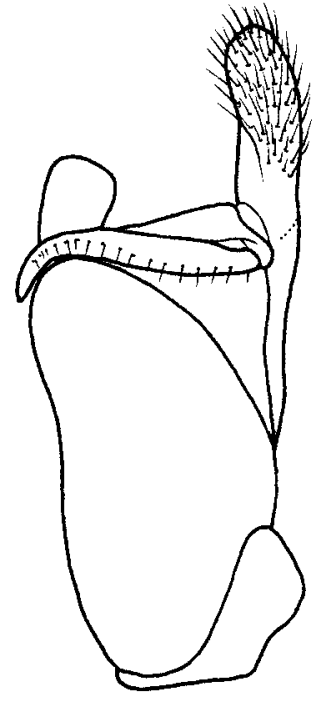

20. mahajanaensis

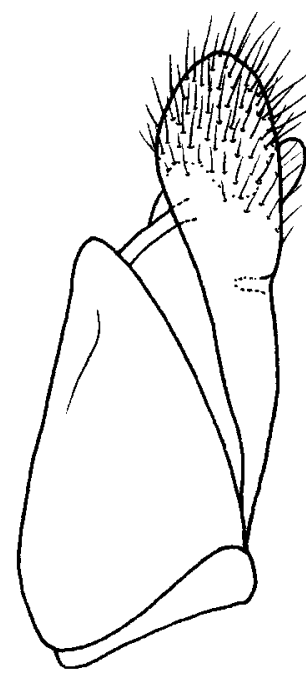

23. nigrimacula

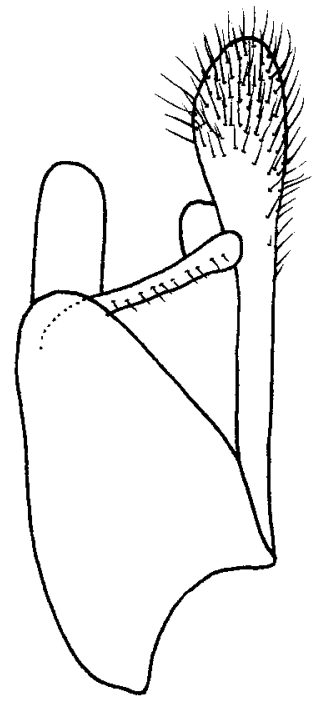

21. micromeria

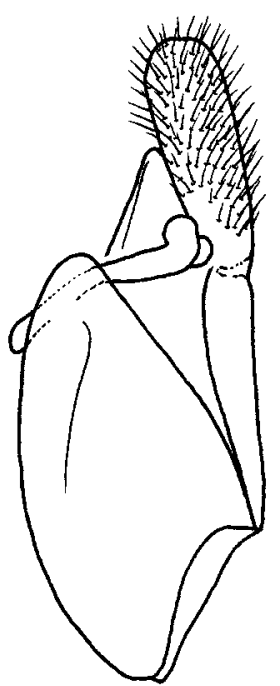

24. toliaraensis

FIGURES 15-25. Male genital capsule, lateral view. Abbreviations: $\mathrm{gc}=$ gonocoxa, $\mathrm{pb}=$ paramere base, $\mathrm{pa}=\mathrm{paramere}$ apical lobe, $\mathrm{pv}=$ penis valve, $\mathrm{v}=$ volsella . 
MA01-01A-01; 1 đ: 1 mi w Sakalava Beach, 30 m, 23-27/i/2001, 1216.11S 4923.25E, Irwin, Schlinger \& Harin'Hala, malaise trap, MA01-04A-02 (BME, CAS).

Distribution. Map 2.

Etymology. Anthobosca fisheri, is named after Brian Fisher, who is responsible for the Madagascar arthropod survey project.

\section{Anthobosca hallucigenia Kimsey, new species}

Figs. 2-4, 7, 17, 27, Map 3

Diagnosis. Males of Anthobosca hallucigenia are so distinctive there is no possibility that they could be confused with any other species. The bright yellow markings, medially protruding and carinate interantennal area, dentate hindfemur and spoon-shaped projections on the metasomal sterna immediately distinguish this species from all other Anthobosca.

Male. Body length 10-11 mm. Head (Fig. 3): inner eye margin with upper third slightly emarginate; flagellomere I $0.8 \mathrm{x}$ as long as broad, flagellomere II $1.4 \mathrm{x}$ as long as broad, flagellomere XI 1.3x as long as broad; flagellomeres $\mathrm{V}-\mathrm{X}$ each with one tyloid; clypeal apex broadly truncate; clypeus and interantennal sclerite strongly projecting, transected by medial longitudinal carina. Mesosoma: hindfemur with strong medial angle on ventral surface. Metasoma: segment 1 longer than broad; sternum II and III each with large, spoon-like medial projection (Fig. 4); sternum VIII thickened apex about twice as long as broad, without spinose apical margin (Fig. 2). Genital capsule (Figs. 7, 17, 27): paramere subtriangular in lateral view, broadly visible in ventral view, with base twice as broad as apex, dististyle apically broadened and ear-like; aedeagus length subequal to volsella, apical lobes short, narrowly separated; volsella vertically bilobate apically, largely obscured by aedeagus and paramere, wrapping around dististyle in lateral view. Punctation: head, mesosoma and metasoma covered with dense contiguous punctures, appearing granular. Vestiture: head and mesosoma with very short golden, erect setae; metasomal setae golden, shorter and appressed. Coloration: body black to darkish brown particularly on mesosoma, with yellow markings: yellow band extending from mid frons to clypeal apex, band along lower two-thirds of inner eye margin; prothoracic notum yellow with yellow lateral spot (lacking in some specimens); pro- and hindcoxae with anterior yellow spot; scutellum and metanotum with large yellow medial spot (small in some specimens); propodeum with small medial and lateral spots; metasomal tergum I with small lateral spot (sometimes absent); sternum I and II with broad transverse medial band, broken medially on sternum II; tergum VI and VII yellow; sternum I posterior declivity yellow; sternum VI with yellow lateral spot; parameres yellow; femora black; tibiae and tarsi dark reddish brown; antenna black to reddish brown; wing membrane brown-tinted, darkest near coastal margin.

Female. Unknown.

Type material. Holotype $\delta^{\top}$ : MADAGASCAR: Toamasina Prov., Andasibe National Park, botanic garden near park entrance, 1-5/ix/2001, 1855.58S 4824.47E, R. Harin'Hala colr., malaise trap, 1025m, MA-01-08B-

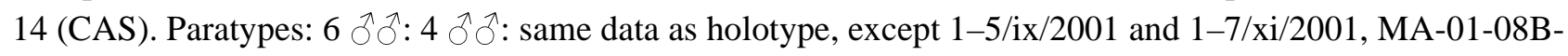
18; 10: Fianarantsoa Prov., Ranomafana National Park, 1130m 27/ii/- 9/iii/2003 2115.05S 4724.43, E R. Harin'Hala colr., malaise trap, MA-02-09B-54; 1 đ: Diego Suarez [Antsiranana] Prov., Montagne National Park, Montagne d'Ambre, 960 m, 26-29/i/2001, 1230.52S 4910.53E, M.E. Irwin, E. I. Schlinger, R. Harin'Hala colrs., malaise trap, MA01-01A-02 (CAS, BME).

Distribution. Map 3.

Etymology. The species epithet, hallucigenia, refers to the bizarre abdominal and facial modifications of the males. 


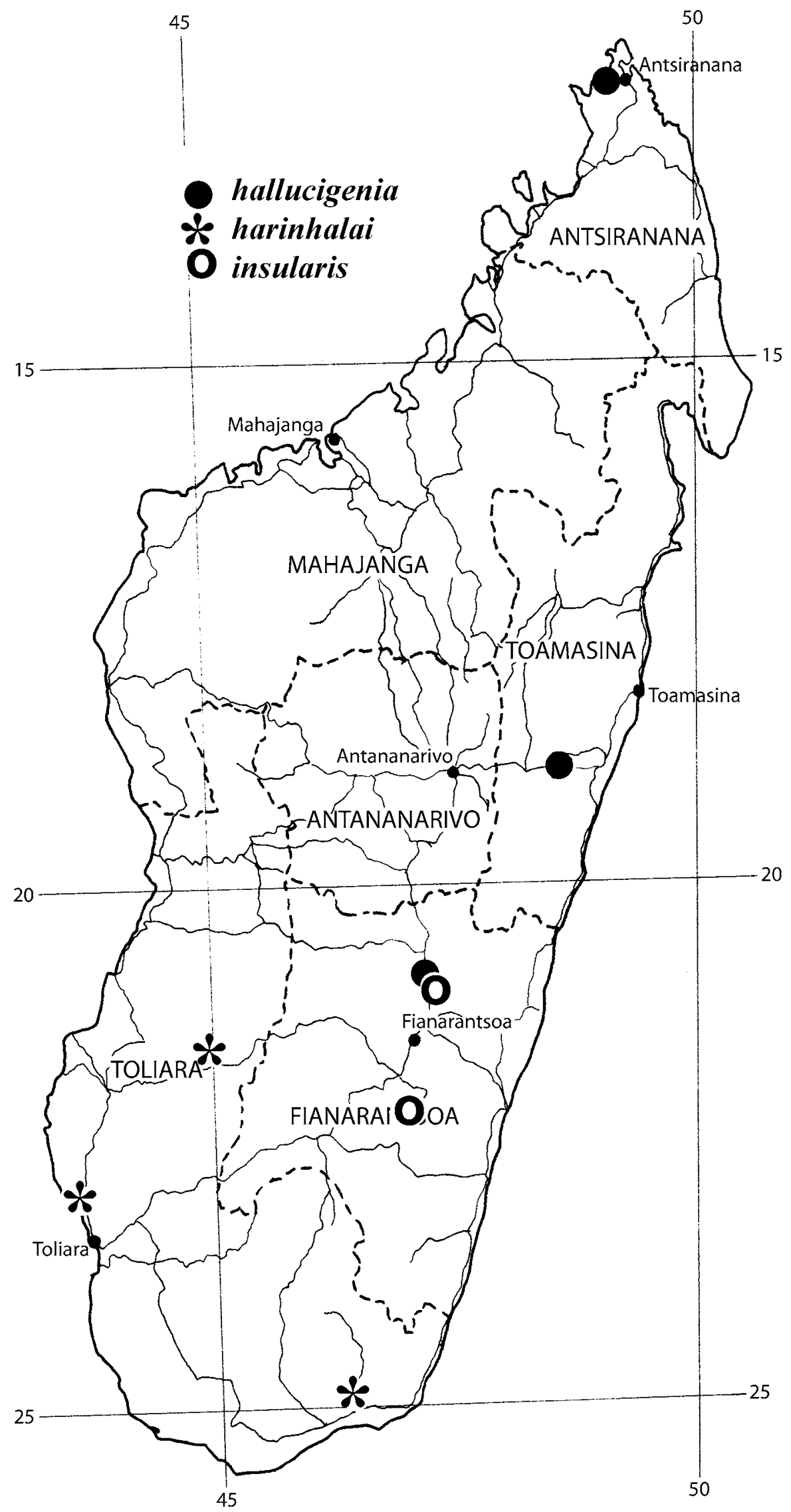

MAP 3. Distribution of Anthobosca hallucigenia Kimsey, new species, Anthobosca harinhalai Kimsey, new species, and Anthobosca insularis F. Smith. 


\section{Anthobosca harinhalai Kimsey, new species}

Figs. 8, 18, 28, Map 3

Diagnosis. Anthobosca harinhalai most closely resembles fisheri, but can be readily distinguished by the bicolored clypeus and largely white mandible and scape.

Male. Body length $7 \mathrm{~mm}$. Head: inner eye margin slightly emarginate; flagellomere I 1.1x as long as broad, flagellomere II 1.5x as long as broad, flagellomere XI 2.6-3.0x as long as broad; flagellomeres viii-x each with one tyloid; clypeal apical truncation slightly indented medially. Mesosoma: hindleg unmodified. Metasoma: segment 1 longer than broad; sternum VIII thickened apex broadly triangular, slightly longer than broad, apical margin spinose. Genital capsule (Figs. 8, 18, 28): gonocoxa broadest basally, strongly narrowed apically in dorsal view; aedeagus broad, about 3.5x as broad as long, apical lobes narrowly separated; volsella dorsal lobe extending diagonally from behind dorsal lobe of gonocoxa toward paramere, largely obscured by paramere and gonocoxa in lateral view; paramere basally twice as long as broad and narrowest submedially apical lobe twice as long as broad, in ventral view. Punctation: body with dense small, contiguous punctures. Vestiture: silvery. Coloration: head, mesosoma and metasoma black, with pale yellow to whitish markings; clypeus usually without pale marks; mandible white with dark apex; underside of scapal apex whitish; whitish band along inner eye margin; flagellum blackish, not bicolored; small whitish spot behind eye near vertex; pronotum with wide transverse whitish band along posterior margin and ventral whitish spot; tegula and wing vein bases whitish; palps and tibial spurs whitish; tarsi pale red; tibiae, femoral apices and trochanters partly whitish to pale red; paramere dististyle brown.

Female. Unknown.

Type material. Holotype $\delta^{\text {: }}$ MADAGASCAR: Toliara Prov. Forêt de Mahavelo Isantoria River, 110m, 28/i-1/ii/2002, 24453S 46926E, Fisher, Griswold et al., malaise trap, BLF5237 (CAS). Paratypes: 10 ठ̊ં; 5

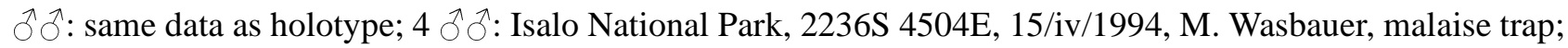
1 ठ̊: Tulear Prov., Mikea Forest nw Manombo, 30m, 2254.22S 4328.53E, 6-16/i/2002, R. Harin'Hala, malaise trap, MA-02-18A-09 (BME, CAS).

Distribution. Map 3.

Etymology. The species is named after the collector, R. Harin'Hala.

\section{Anthobosca insularis F. Smith}

Figs. 1, 9, 19, 29, Map 3

Myzine insularis Smith 1879:178. Holotype $q$; Madagascar (LONDON).

Diagnosis. Anthobosca insularis is the largest bodied species of Anthobosca; males range from 10-20 mm long and females from 20-30 mm in length. The size, amber wings and lack of whitish markings on the body will immediately distinguish it from all other species in Madagascar or elsewhere.

Male. Body length $\mathrm{mm}$. Head: inner eye margin slightly emarginate; clypeus evenly convex medially, apical truncation broader than interantennal distance, medially indented; flagellomere I 1.4x as long as broad; flagellomere II 1.7x as long as broad; flagellomere XI 2.9-3.0x as long as broad; flagellum without tyloids. Mesosoma: hindleg unmodified. Metasoma: segment 1 longer than broad; segment 1 much broader than long; sternum VIII apical rim thickened, without marginal spines (Fig. 1). Genital capsule (Figs. 9, 19, 29): gonocoxa broadest medially and elongate ovoid in dorsal view; aedeagus broadest apically, about 3.7x as broad as long, apical lobes short, broad, narrowly separated; volsella dorsal lobe nearly erect behind dorsal lobe of gonocoxa extending toward paramere, obscured by paramere and gonocoxa in lateral view; paramere basally nearly $3 \mathrm{x}$ as long as broad and narrowest subbasally apical lobe $2.2 \mathrm{x}$ as long as broad, in ventral view. Punctation: dense, tiny. Vestiture: silvery on head and mesosoma, brown on metasoma. Coloration: body black, except head and sometimes pronotum dark reddish brown, with pale band along inner and outer eye 
margins, wing membrane dark amber tinted.

Female. Body length $26-28 \mathrm{~mm}$. Same as male except flagellomere I 1.5x as long as broad; flagellomere II as long as broad, flagellomere X 3x as long as broad, body blackish, vestiture black.

Distribution. This species has only been collected in Ranomafana National Park and nearby in Fianarantsoa Prov. (Map 3). However, it must be very abundant throughout the year in these sites; more than 216 specimens were examined, collected in nearly every month. Interestingly only three of these hundreds of specimens were female.

\section{Anthobosca madecassa Krombein}

Anthobosca madecassa Krombein 1949:52. Holotype 9 ; Madagascar: Bekily (ITHACA).

Map 4

Diagnosis. Female madecassa are distinctive and are easily distinguished by the red head, dorsally red and ventrally black mesosoma, and metasoma with large, pale lateral spots on terga II and III.

Male. Unknown.

Female. Body length 5-8 mm. Head: flagellomere I 1.3x as long as broad; flagellomere II as long as broad; flagellomere X 2.6x as long as broad; clypeus broadly truncate apically. Punctation: punctures sparse and tiny on head and mesosoma, tiny and dense on metasoma. Vestiture: body with long silvery setae. Coloration: head, scape and pedicel red; mesosoma red dorsally, with black venter; propodeum red, black in one specimen; tibial spurs whitish; metasoma black to dark brown, with large white lateral spot on tergum II and III.

Distribution. Toliara Prov.: Bekily, Lake Ranobe, Ranobe, 18 km nnw Betroka; Antsiranana Prov., 7 km n Joffreville, Montagne d'Ambre National Park, $14 \mathrm{~km}$ ssw Antsiranana Nord; 9 q $q$ were studied in addition to the type (Map 4). Specimens were collected in the months of October, November and January through June.

\section{Anthobosca mahajangaensis Kimsey, new species}

Figs. 10, 20, 30, Map 4

Diagnosis. Anthobosca mahajangaensis most closely resembles toliaraensis based on the structure of the male genitalia and dimensions of the flagellomeres I, II and IX. However, mahajangaensis can be distinguished by the entirely white clypeus and white paramere apex.

Male. Body length 5-10 mm. Head: inner eye margin slightly emarginate; flagellomere I 1.2x as long as broad, flagellomere II 1.5-1.6x as long as broad, flagellomere XI 2.6x as long as broad; flagellomeres viii-X each with one tyloid; clypeus evenly convex medially, apex truncate. Mesosoma: hindleg unmodified. Metasoma: segment 1 longer than broad; sternum VIII thickened apex about 1.5x as broad as long, apical margin spinose. Genital capsule (Figs. 10, 20, 30): gonocoxa broadest medially, broadly rounded apically in dorsal view; aedeagus narrow, $7 \mathrm{x}$ as broad as long, apical lobes broadly separated; volsella dorsal lobe extending horizontally across top of gonocoxa extending alongside paramere in lateral view; paramere basal part 3.8-4.0x as long as broad and narrowest subapically apical lobe slightly less than twice as long as broad. Punctation: body with dense, small, contiguous punctures. Vestiture: silvery. Coloration: body black, with pale yellow to whitish markings; clypeus entirely white; palps white; mandible white, with dark reddish brown tip; flagellum bicolored black above, paler beneath; scutum, scutellum and metanotum with medial whitish spot; femora and tibiae largely red, with some white; fore and midtarsi whitish; hindbasitarsus whitish basally becoming dark reddish brown apically; apical hindtarsomeres dark brown to black; paramere apex whitish.

Female. Unknown. 


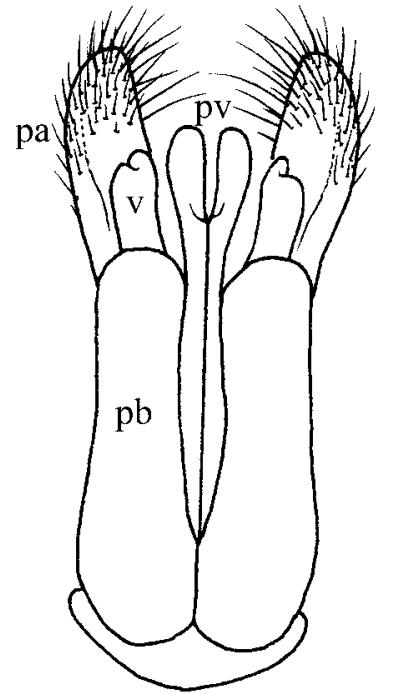

25. castanea

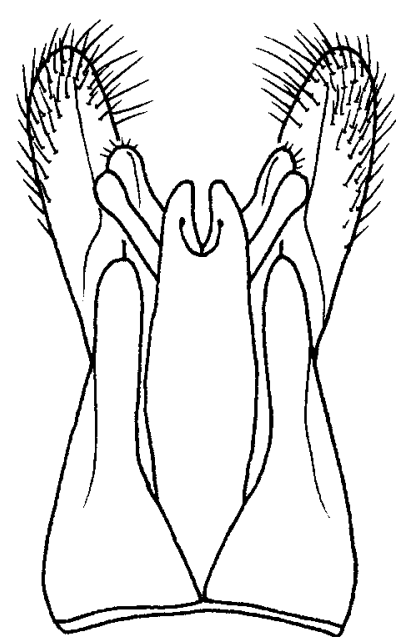

28. harinhalai

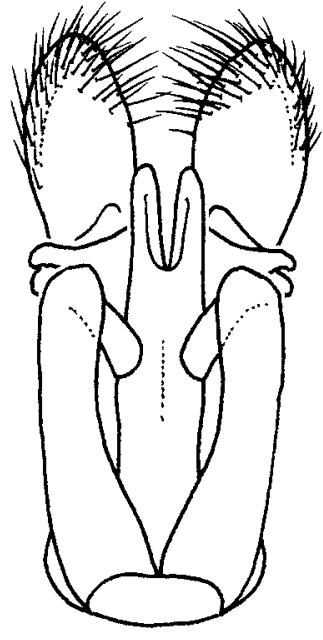

26. fisheri

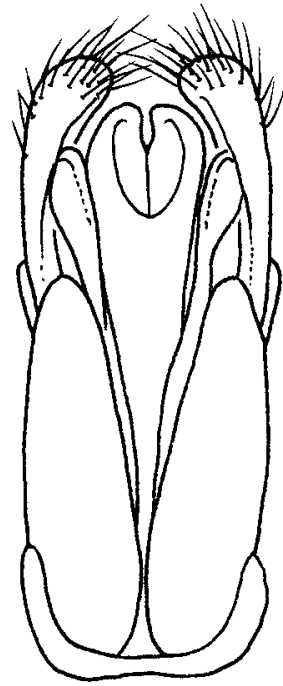

29. insularis

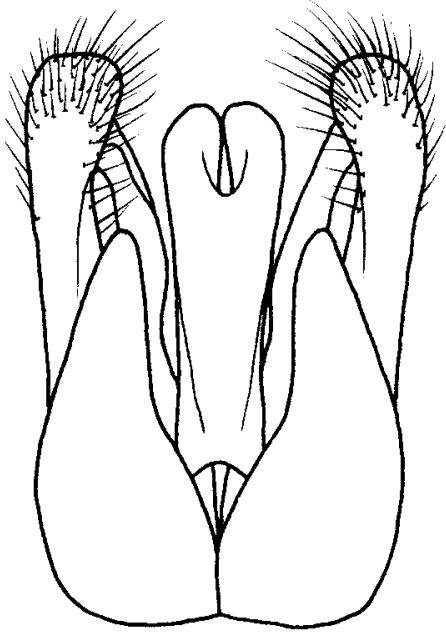

27. hallucigenia

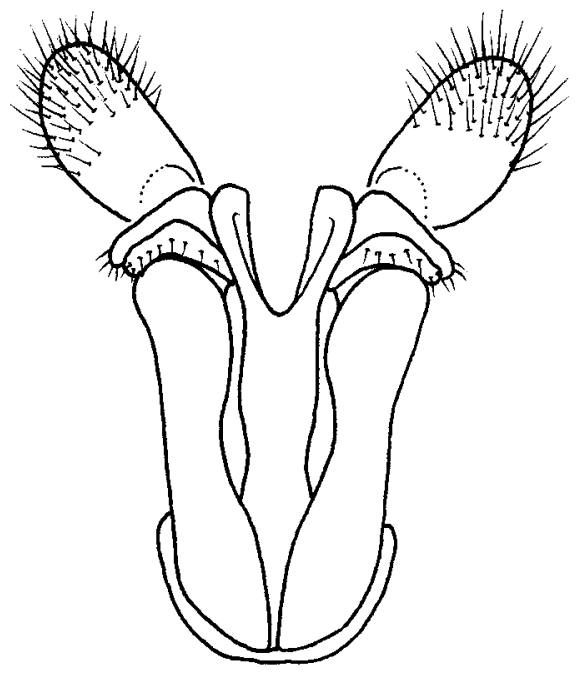

30. mahajanaensis

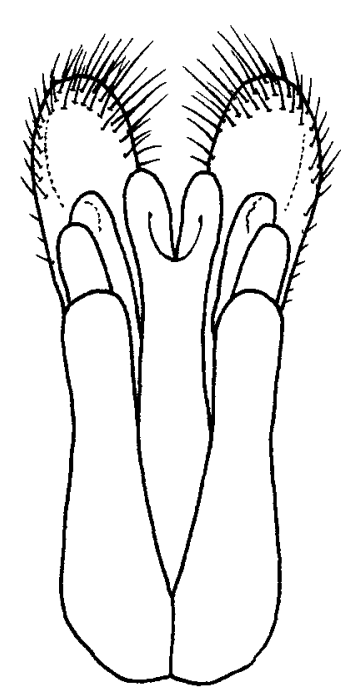

31. micromeria

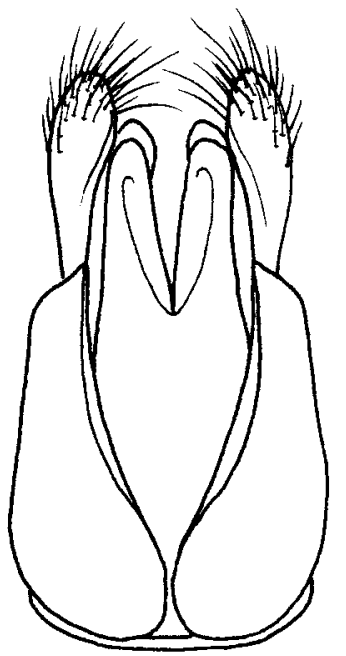

32. namorokanesis

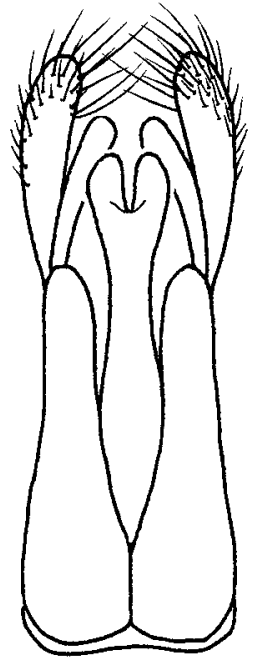

33. nigrimacula

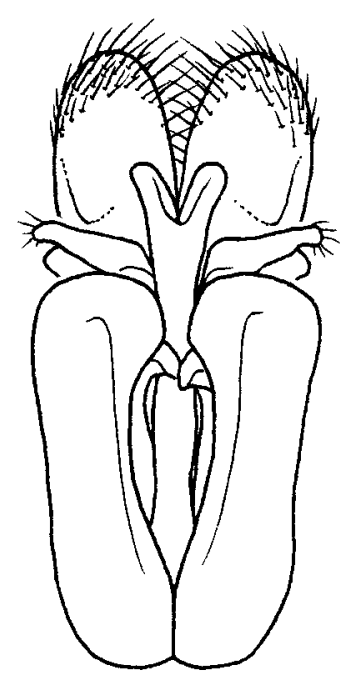

34. toliaraensis

FIGURES 26-35. Male genital capsule, dorsal view. Abbreviations: gc = gonocoxa, $\mathrm{pb}=$ paramere base, $\mathrm{pa}=$ paramere apical lobe, $\mathrm{pv}=$ penis valve, $\mathrm{v}=$ volsella. 


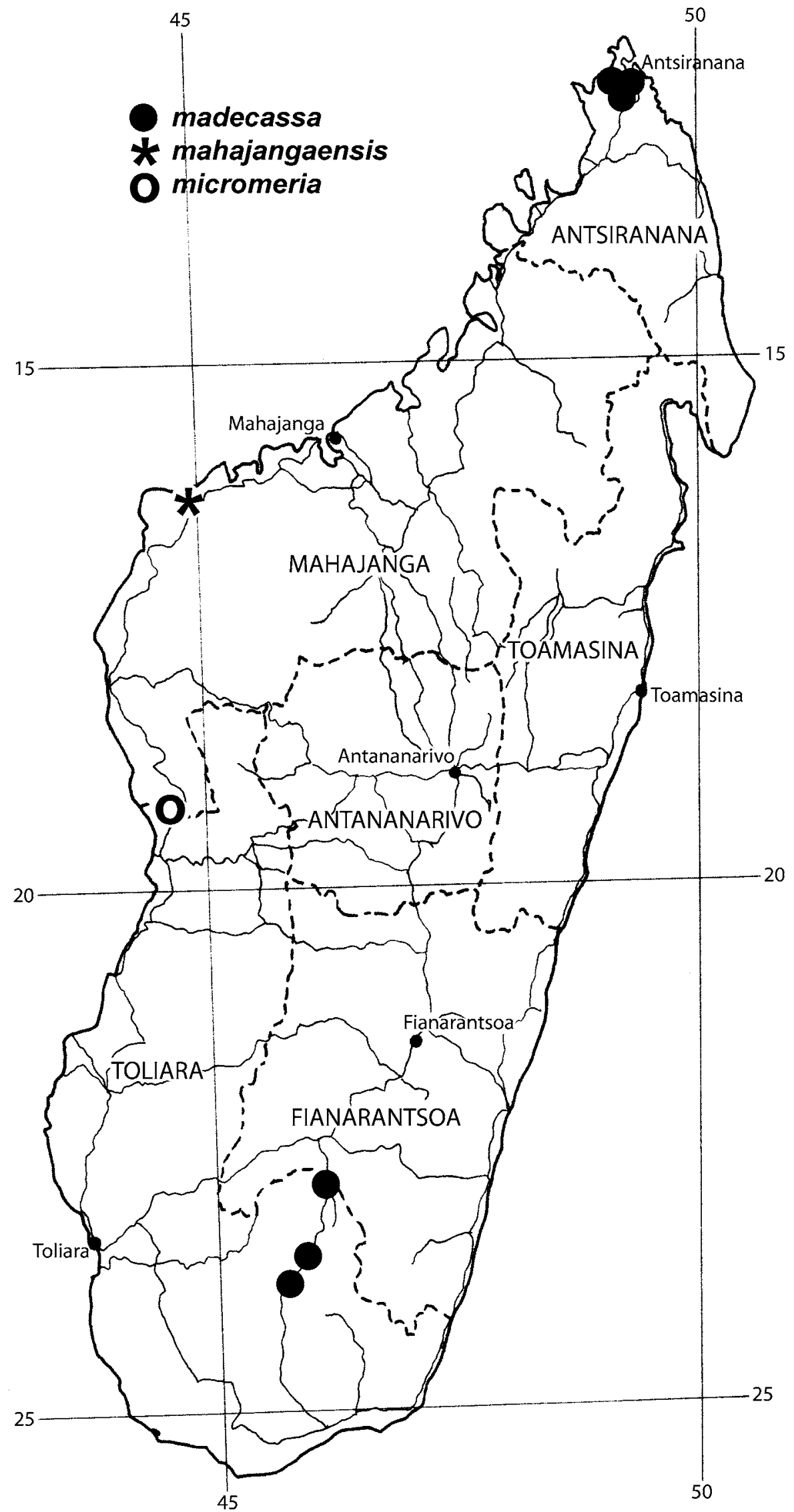

MAP 4. Distribution of Anthobosca madecassa Krombein, Anthobosca mahajangaensis Kimsey, new species, and Anthobosca micromeria Bartalucci. 
Type material. Holotype $\delta^{\top}$ : MADAGASCAR: Mahajanga Prov., Parc National de Baie de Baly, $12.4 \mathrm{~km}$ 337 nnw Soalala, 10m, 26-30/xi/2002, 160036S 0451554E Fisher, Griswold et al. YPT, BLF6817 (CAS). Paratypes: $4 \widehat{\partial}$, same data as holotype (BME, CAS).

Distribution. Map 4.

Etymology. The species name derives from Mahajanga Province where the type series was collected.

\section{Anthobosca micromeria Bartalucci}

Figs. 11, 21, 31, Map 4

Anthobosca micromeria Bartalucci 2005:1083. Holotype ở; Madagascar: Tulear Morondava (LONDON).

Diagnosis. The most distinctive feature of micromeria is flagellomere VIII lacking a tyloid. Other diagnostic features include the all-white clypeus and paramere apex, and the apical flagellomere twice as long as broad.

Male. Body length 3-10 mm. Head: inner eye margin slightly emarginate; flagellomere I as long as broad; flagellomeres II and XI 1.6-2x as long as broad, flagellomeres ix-x each with one tyloid; clypeal apex narrowly truncate apically, with short ventrally facing flattened surface. Mesosoma: hindleg unmodified. Metasoma: segment 1 longer than broad; sternum VIII thickened apex broadly triangular, slightly longer than broad, apical margin spinose. Genital capsule (Figs.11, 21, 31): gonocoxa broadest basally, narrowed medially, broadly rounded apically in dorsal view; aedeagus narrow, about 10x as broad as long, apical lobes narrowly separated; volsella dorsal lobe extending horizontally from behind dorsal lobe of gonocoxa toward paramere; paramere basally strongly tapering toward base, $4 \mathrm{x}$ as long as broad, apical lobe about twice as long as broad in ventral view. Punctation: dense, tiny, nearly contiguous. Vestiture: silvery. Coloration: head, mesosoma and metasoma black, with pale yellow to whitish markings; clypeus white; mandible white, with dark apex; underside of scapal apex whitish; whitish band along inner eye margin; flagellum bicolored, top black, underside orange; small whitish spot behind eye near vertex; pronotum with wide transverse whitish band along posterior margin and ventral whitish spot; scutum with medial whitish spot; tegula and wing vein bases yellowish to white; tarsi, palps and tibial spurs whitish; tibiae and trochanters partly whitish; femora apically and basally whitish; paramere apical lobe whitish.

Female. Unknown.

Distribution. Mahajanga Prov.: Forêt de Tsimembo, Morondava. Three specimens were examined in addition to the holotype (Map 4). Specimens were collected in November, February and April.

\section{Anthobosca namorokaensis Kimsey, new species Figs. 12, 22, 32, Map 5}

Diagnosis. The flat, brown clypeus is the most distinctive feature of namorokaensis. Otherwise, the white dorsal paramere lobe and flagellomere XI 2.6x as long as broad are features shared with mahajangaensis.

Male. Body length 8-9 mm. Head: inner eye margin slightly emarginate; flagellomere I $1.2 \mathrm{x}$ as long as broad, flagellomere II 1.5x as long as broad, flagellomere XI 2.6x as long as broad; flagellomeres viii-x each with one tyloid; clypeus medially flattened, strongly depressed sublaterally, apex bilobate. Mesosoma: hindleg unmodified. Metasoma: segment 1 longer than broad; sternum VIII thickened apex broadly triangular, broader than long, apical margin spinose. Genital capsule (Figs. 12, 22, 32): gonocoxa broadest basally, strongly narrowed apically in dorsal view; aedeagus broad, about twice as broad as long, apical lobes broadly separated; volsella dorsal lobe extending horizontally from behind dorsal lobe of gonocoxa toward paramere; paramere basal part twice as long as broad and narrowest subapically apical lobe $2.6 \mathrm{x}$ as long as broad in ventral view. Punctation: body with dense small, contiguous punctures. Vestiture: silvery. Coloration: head and mesosoma black, metasoma dark brown, with pale brown to whitish markings; clypeus with large, 
irregular pale brown medial spot; mandible whitish basally; underside of scape whitish; whitish band along inner eye margin; flagellum bicolored, black above, underside reddish; small whitish spot behind eye near vertex; pronotum with transverse whitish band along posterior margin; tarsi, palps and tibial spurs whitish; tibiae and trochanters partly whitish; tegula white; wing veins whitish near base, apically dark brown; wing membrane untinted; paramere apical lobe whitish.

Female. Unknown.

Type material. Holotype $\delta^{\Uparrow}$ : MADAGASCAR: Mahajanga Prov., Namoroka National Park, 16.9 km, 317 nw Vilanandro, 12-16/xi/2002, 1624.24S 4518.36E, Fisher, Griswold et al., malaise trap, tropical dry forest, 100 m, BLF6581 (CAS). Paratypes: 2 ठ઼, same data as holotype (BME, CAS).

Distribution. Map 5.

Etymology. This species is named after the national park where the type series was collected.

\section{Anthobosca nigrimacula Kimsey, new species}

Figs. 13, 23, 33, Map 5

Diagnosis. Diagnostic features of Anthobosca nigrimacula include flagellomere VII with a small tyloid, and flagellomere II 1.5x as long as broad. The species most closely resembles toliarensis and castanea based on the short flagellomere XI, black and white clypeus, bicolored flagellum and apically white paramere.

Male. Body length 7-8 mm. Head: inner eye margin slightly emarginate; flagellomere I 1.2x as long as broad, flagellomere II 1.5x as long as broad, flagellomere XI twice as long as broad; flagellomeres vii-xi each with one tyloid; clypeus evenly convex medially, apex narrowly truncate. Mesosoma: hindleg unmodified. Metasoma: segment 1 longer than broad; hypopygium apically narrowly rounded, margin spinose. Genital capsule (Figs. 13, 23, 33): gonocoxa broadest apically, nearly parallel-sided in dorsal view; aedeagus narrow, about 7x as broad as long, apical lobes narrowly separated; volsella dorsal lobe extending diagonally from behind dorsal lobe of gonocoxa toward paramere, largely obscured by paramere and gonocoxa in lateral view; paramere basal part $3 \mathrm{x}$ as long as broad and narrowest submedially apical lobe $2.4 \mathrm{x}$ as long as broad in ventral view. Punctation: Body with dense small, contiguous punctures. Vestiture: silvery. Coloration: head, mesosoma and metasoma black, with pale yellow to whitish markings; clypeus with irregular whitish medial and lateral spots; mandible white with dark apex; underside of scapal apex whitish; whitish band along inner eye margin; flagellum bicolored, top black, underside orange; small whitish spot behind eye near vertex; pronotum with wide transverse whitish band along posterior margin and ventral whitish spot; scutum with medial whitish spot; Tegula and wing vein bases white; tarsi, palps and tibial spurs whitish; tibiae and trochanters partly whitish; paramere apical lobe whitish.

Female. Unknown.

Type material. Holotype $\delta^{7}$ : MADAGASCAR: Toliara Prov., Réserve Spéciale de Cap Sainte Marie, 12.3km 262 w Marovato, 200m, 11-15/ii/2002, 253454S 45106E, Fisher Griswold et al., malaise trap, BLF5504 (CAS). Paratype ${ }^{\top}$ : same data as holotype (CAS).

Distribution. Map 5.

Etymology. The species name refers to the coloration of the clypeus.

\section{Anthobosca toliaraensis Kimsey, new species}

Figs. 14, 24, 34, Map 5

Diagnosis. Anthobosca toliaraensis most closely resembles castanea, based on the short flagellomere XI, whitish paramere apical lobe and flagellomere II more than $1.5 \mathrm{x}$ as long as broad. It can be distinguished from that species by the horizontally oriented volsellar apical lobe. 


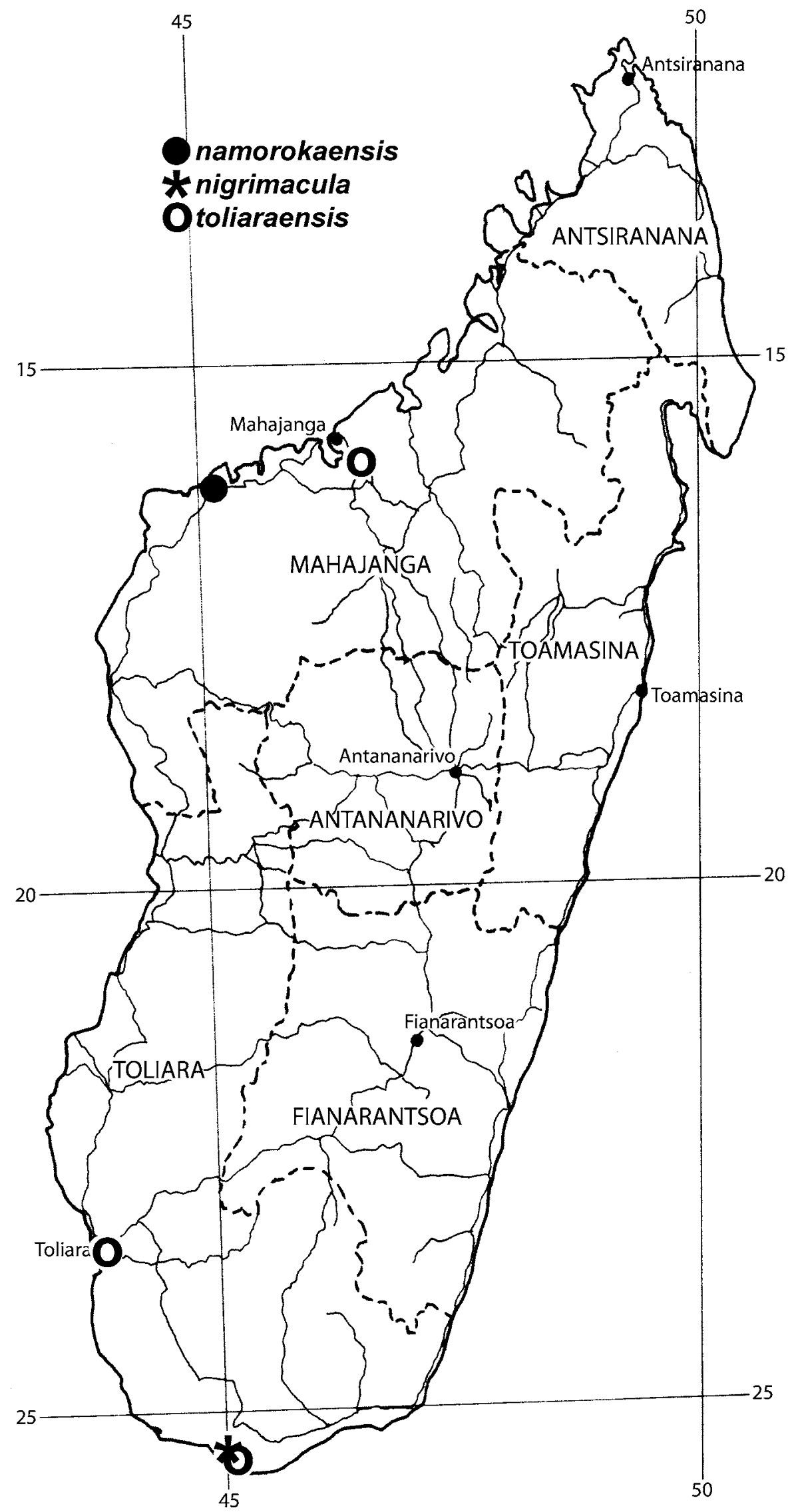

MAP 5. Distribution of Anthobosca namorokaensis Kimsey, new species, Anthobosca nigrimacula Kimsey, new species, and Anthobosca toliaraensis Kimsey, new species. 
Male. Body length $5 \mathrm{~mm}$. Head: inner eye margin slightly emarginate; flagellomere I $1.2 \mathrm{x}$ as long as broad, flagellomere II 1.6-2.0x as long as broad, flagellomere XI twice as long as broad; flagellomeres viii-X each with one tyloid; clypeus medially convex, apex narrowly truncate. Mesosoma: hindleg unmodified. Metasoma: segment 1 longer than broad; sternum VIII apically thickened, subtriangular, apical margin rimmed with short thick spines. Genital capsule (Figs. 14, 24, 34): gonocoxa broadest apically, broadly rounded apically in dorsal view; aedeagus narrow, 10x as broad as long, apical lobes narrowly separated; volsella dorsal lobe extending horizontally behind top of gonocoxa extending alongside paramere in lateral view; paramere basally $3 \mathrm{x}$ as long as broad, narrowest subapically and subbasally, apical lobe $2.3 \mathrm{x}$ as long as broad. Punctation: Body with dense small, contiguous punctures. Vestiture: silvery. Coloration: head, mesosoma and metasoma black, with pale yellow to whitish markings; clypeus white; mandible white with dark apex; scape ventrally white; whitish band along inner eye margin; flagellum black; small whitish spot behind eye near vertex; pronotum with wide transverse whitish band along posterior margin and ventral whitish spot; scutum with medial whitish spot; tegula and wing vein bases white; tarsi, palps and tibial spurs whitish; tibiae and trochanters partly whitish; paramere apical lobe whitish.

Female. Unknown.

Type material. Holotype $\delta^{\Uparrow}$ : MADAGASCAR: Toliara Prov., $12 \mathrm{~km}$ se Tulear, 2351S 4322E, 23/iii/1994,

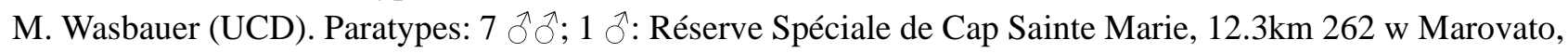
200m, 11-15/ii/2002, 253454" S 45106", Fisher, Griswold et al., MT, BLF5504; 6 ð̊: Mahajanga Prov., Parc National d'Ankarafantsika, Ampijoroa Station Forestière, 40 km nw Andranofasika, 130 m, 26/iii-1/iv/2001, 1619.15S 4648.38E, Fisher, Griswold et al., BLF3520 (BME, CAS).

Distribution. Map 5.

Etymology. The species name is derived from Toliara Province.

\section{Acknowledgements}

Specimens in this study were obtained primarily from the California Academy of Sciences Arthropods of Madagascar Project and the Bohart Museum of Entomology. The Arthropods of Madagascar Project was sponsored by the U.S. National Science Foundation, Biotic Surveys and Inventories Program (BSI 0072713), McBean Family Foundation, Lakeside Foundation, the Schlinger Foundation, and the South African Museum. Holotypes and paratypes are deposited in the California Academy of Sciences, San Francisco (CAS) and the Bohart Museum of Entomology, University of California, Davis (BME). The holotypes of Anthobosca madecassa Krombein and Anthobosca micromeria Bartalucci were borrowed from the Cornell University Entomology Museum, Ithaca, New York (Richard Hoebeke) (ITHACA) and the Natural History Museum, London (Richard Brown) (LONDON) respectively.

\section{References}

Bartalucci, M.B. (2005) Anthoboscinae and Myzininae (Hymenoptera, Tiphiidae) from Madagascar. Linzer Biologische Beiträge, 2005, 1077-1097.

Kimsey, L.S. (1996) Phylogenetic relationships of the thynnine wasp tribe Rhagigasterini. Journal of Hymenoptera Research, 5, 80-99.

Kimsey, L.S. \& Bohart, R.M. (1991 [1990]) The Chrysidid Wasps of the World. Oxford University Press, New York, ix+652 pp.

Krombein, K.V. (1949) Studies in the Tiphiidae. VII. The Madagascan species. Proceedings of the Entomological Society of Washington, 51, 45-73.

Magretti, P. (1884) Risultati di raccolte imenotterologische nell'Africa Orientale. Annali del Museo Civico di Storia Naturelle di Genova (2 $\left.2^{\mathrm{a}}\right), 1,523-567$.

Pate, V.S.L. (1947) A conspectus of the Tiphiidae, with particular reference to the Nearctic forms. Journal of the New York Entomological Society, 55, 115-145.

Smith, F. (1879) Descriptions of New Species of Hymenoptera in the British Museum, London. 240 pp. 